\title{
Lipid Peroxidation After Ionizing Irradiation Leads to Apoptosis and Autophagy
}

\author{
Juliann G. Kiang, Risaku Fukumoto and Nikolai V. Gorbunov
}

Additional information is available at the end of the chapter

http://dx.doi.org/10.5772/48189

\section{Introduction}

A living cell is a dynamic biological system composed primarily of nucleic acids, carbohydrates, lipids, and proteins that structurally and functionally interact with many other molecules--organic and inorganic--to carry out normal cell metabolism. Exposure of a cell to radiation can both directly and indirectly alter molecules within the cell to affect cell viability. Radiation energy absorbed by tissues and fluids is dissipated by the radiolysis of water molecules and biomolecules [1-3]. These reactions result in redox-reactive products such as hydroxyl radical $\left(\mathrm{HO}^{*}\right)$, hydrogen peroxide $\left(\mathrm{H}_{2} \mathrm{O}_{2}\right)$, hydrated electron (e-aq), and an array of biomolecule-derived carbon-, oxygen-, sulfur-, and nitrogen-centered radicals (i.e., $\mathrm{RC}^{*}, \mathrm{RO}^{*}, \mathrm{RS}^{*}$, and $\mathrm{RN}^{*}$ ) that can in turn lead to the formation of organic peroxides and superoxide anion radicals $\left(\mathrm{O}_{2}{ }^{*}\right.$ ) in the presence of molecular oxygen $[3,4]$.

While the strongly electrophilic $\mathrm{HO}^{*}$ has the capacity to damage molecules like polypeptides, amino acids, and polyunsaturated fatty acids (PUFAs) directly, the alterations caused by peroxide and superoxide radicals are usually produced indirectly via Fenton-type reactions $[1-3,5]$. It is the interaction of these radiation-induced free radicals with important biomolecules within the cell that is the basis of the cellular sensitivity to radiation.

Free radical reactions generated after short-term radiation exposure are often quickly terminated by antiradical/antioxidant redox cycles. However, in certain cases and certain cellular environments, free radicals can initiate self-propagating chain reactions that can magnify the effects of the initial oxidations induced by radiation, leading to major disruptions that affect basic cell function [4, 6-9]. This especially true in cellular structures rich in poly-unsaturated fatty acids (PUFAs), such as cellular membranes, where radiation exposure can induce lipid peroxidation chain reactions that trigger reactions both within and beyond of the membrane [see 10-13]. Although the chemical mechanisms by which radiation induces the formation of redox-reactive products in cells are fairly well- 
understood, many of the mechanisms by which they impact specific cellular processes to produce radiation injury are only beginning to be elucidated.

Lipid peroxidation is a process in which free radicals remove electrons from lipids, producing reactive intermediates that can undergo further reaction. Cellular membranes, because of their high lipid content, are especially susceptible to damage. Because lipid peroxidation reactions can alter the structure and function of critical membrane lipids, they can lead to cell injury and cell death.

Lipid peroxidation reactions take place in three steps. The first step is initiation, which produces a fatty acid radical. In polyunsaturated fatty acids, methylene groups next to carbon-carbon double bonds possess especially reactive hydrogen atoms. Lipid peroxidation is most commonly initiated when reactive oxygen species (ROS) such as $\mathrm{OH}$. and $\mathrm{HO}_{2}$ interact with a reactive methylene hydrogen atom to produce water and a fatty acid radical:

$$
\mathrm{PUFA}+\mathrm{OH} \cdot \rightarrow \mathrm{PUFA}^{*}+\mathrm{H}_{2} \mathrm{O}
$$

The second step is propagation. Molecular oxygen reacts with the unstable lipid radical to produce a lipid peroxyl radical. This radical is also unstable; it reacts readily with an unsaturated fatty acid to regenerate a new fatty acid radical as well as a lipid peroxide. The generation of the new fatty acid radical in this step reinitiates the cycle. For this reason, this series of reactions is referred to as a lipid peroxidation chain reaction.

$$
\begin{gathered}
\text { PUFA }^{*}+\mathrm{O}_{2} \rightarrow \text { PUFAOO }^{*} \\
\text { PUFAOO }^{*} \rightarrow \text { Fenton } \rightarrow \text { HO-PUFA }^{*}+\mathrm{OH}^{-}
\end{gathered}
$$

The third step is termination. As the chain reaction continues, an increasing concentration of lipid radicals are produced, thereby increasing the probability two lipid radicals will react with each other, which can produce a non-radical species. This constitutes a chain-breaking step, which in combination with the activity of natural radical scavenging molecules in cellular systems ultimately quells the chain reaction.

There are four types of radiation capable of ionizing, and thus damaging, target molecules via mechanisms such as lipid peroxidation: alpha particles, beta particles, gamma rays, and neutrons. Gamma radiation has been shown to increase lipid peroxidation in a variety of biological systems. After gamma radiation exposure, levels of the lipid peroxidation indicator MDA have been shown to increase in brain [14], liver [15-19], lens [20], serum [21], and skeletal muscle [22] of rats as well as in bacteria [23].

The possibility of exposure to radiation doses significant enough to cause lipid peroxidation leading to tissue injury is more than a hypothetical hazard. It is estimated that more than $50 \%$ of cancer patients receive radiotherapy at some point during the course of their disease, and these exposures can injure normal tissues [24, 25]. Potentially harmful radiation exposures after a nuclear power plant accident are also possible, either as a plant worker or a citizen who lives in or moves through fallout areas. Such exposures are unlikely; however, 
as the Fukushima, Japan, reactor incident showed, the threat is still very real. The threat of general exposure to radiation via a nuclear or radionuclide-based terrorist device is unfortunately also a real-world scenario. In order to provide public health protection in such cases, it is important to understand more about how radiation affects cells and tissues and learn how to ameliorate radiation injury.

Living organisms have evolved a variety of free radical-scavenging molecules to help protect the cell membrane from damage. Endogenous antioxidants include the enzymes superoxide dismutase (SOD), catalase, and peroxidase. Other antioxidants such as exogenously derived vitamin E can also play a role.

Free radical-mediated lipid peroxidation is harmful not only because damaged lipids disrupt membrane structure and function, but also because the process produces potentially mutagenic and carcinogenic byproducts [26]. One such product is the highly reactive carbonyl compound, malondialdehyde (MDA), which can react with deoxyadenosine and deoxyguanosine in DNA to form DNA adducts, primarily pyrimido[1,2-a]purin-10(3H)-one $\left(\mathrm{M}_{1} \mathrm{G}\right)[23,26]$. $\mathrm{M}_{1} \mathrm{G}$ toxicity has been demonstrated in experiments with glutathione peroxidase 4 knockout mice, which have a diminished capacity to protect themselves from lipid peroxidation and thus $\mathrm{M}_{1} \mathrm{G}$ toxicity; mice with this lethal phenotype do not survive past embryonic day 8 [27].

Lipid peroxidation reactions can occur at the both the cell membrane and mitochondria membranes, and either can subsequently trigger cell death through apoptosis and/or autophagy [28]. Apoptosis is typically executed by caspases, which are cysteine aspartic acid-specific proteases that cleave an amino acid sequence-motif located N-terminal to a specific aspartic acid residue. Caspases can be broadly divided into two functional subgroups: (1) those activated during apoptosis (caspases -2, -3, -6, -7, -8, -9, and -10) ; and (2) those implicated in the processing of proinflammatory cytokines during responses (caspases -1, -4, and -5) [29-31].

The apoptosis process can follow two pathways, extrinsic and intrinsic. The extrinsic pathway involves the activation of pro-caspase- 8 by external, typically molecular signals such as FAS ligand binding to FAS or TNF binding to TNF receptors on the cell membrane. Through a series of steps pro-caspase- 8 becomes activated caspase- 8 , which then acts on the mitochondrial membrane either directly or via the activation of caspase-3. Subsequent steps then follow those described for the intrinsic pathway. The intrinsic pathway involves mitochondria directly. When mitochondria are under stress, cytochrome $\mathrm{c}$ is released from the mitochondria. The released cytochrome c conjugates with Apf- 1 and caspase- 9 tin the cytoplasm to form apoptosomes, which in turn activate caspase-3 and -7. Activated caspase- 3 then activates caspase-2, -6, -8, and -10. It should be noted that caspaseindependent apoptosis pathways also exist, such as the intrinsic, apoptosis inducible factor (AIF) pathway and the intrinsic, mitochondria-derived endonuclease G-related pathway [29-31].

Autophagy is a catabolic process involving the bulk degradation of cellular constituents in lysosomes [32]. Autophagy under normal conditions is a cytoprotective process involved in 
tissue remodeling, recovery, and rejuvenation. Autophagy dynamics in mammalian cells are well-described in several recent reviews [33-37]. The autophagic pathway is complex. To date there are over thirty genes identified in mammalian cells as regulators of various steps of autophagy. The misregulation of the autolysosomal pathway during autophagy can eventually cause cell death either by triggering apoptosis in apoptosis-sensitive cells or as a result of destructive self-digestion [38]. Light chain 3 (LC3) is a protein involved in the formation of autophagosomes in mammalian cells that serves as a biomarker for occurrence of autophagy [13].

Given the widespread potential for cellular damage from lipid peroxidation after exposure to ionizing radiation, we hypothesize that ionizing radiation-induced lipid peroxidation leads to caspase-mediated apoptotic cell death and LC-3-mediated autophagic cell death. The objective of this current chapter is to provide evidence of this hypothesis. We used human Jurkat $\mathrm{T}$ cultured cells and mouse ileum to investigate the relationship between lipid peroxidation and cell death both in vitro and in vivo.

\section{Experimental procedures and technical approach}

\subsection{Cell culture}

Human Jurkat T cells (American Type Cell Collection, Rockville, MD, USA) were grown in $75 \mathrm{~cm}^{2}$ tissue culture flasks (Costar, Cambridge, MA, USA) containing RPMI 1640 medium supplemented with $0.03 \%$ glutamine, $4.5 \mathrm{~g} / \mathrm{L}$ glucose, $25 \mathrm{mM}$ HEPES, $10 \%$ fetal bovine serum, penicillin $(50 \mu \mathrm{g} / \mathrm{mL})$, and streptomycin $(50 \mathrm{U} / \mathrm{mL})$ (Gibco/BRL, Gaithersburg, MD, USA). Cells were incubated in a $5 \% \mathrm{CO} 2$ atmosphere at $37^{\circ} \mathrm{C}$ and fed every $3-4 \mathrm{~d}$.

\subsection{Animal}

CD2F1 male mice (25-30 g) were purchased from Harlan Laboratories (Indianapolis, IN). All mice were randomly assigned to experimental groups. Eight mice were housed per filtertopped polycarbonate cage (MicroIsolator) in conventional holding rooms. Rooms were provided 20 changes per hour of $100 \%$ fresh air, conditioned to $72 \pm 2{ }^{\circ} \mathrm{F}$ and a relative humidity of $50 \pm 20 \%$. Mice were maintained on a 12-h light/dark, full-spectrum light cycle with no twilight. Research was conducted in a facility accredited by the Association for Assessment and Accreditation of Laboratory Animal Care-International (AAALAC-I). All procedures involving animals were reviewed and approved by the Armed Forces Radiobiology Research Institute (AFRRI) Institutional Animal Care and Use Committee.

\subsection{Radiation exposure}

\subsubsection{Cell culture}

Radiation exposures were conducted using AFRRI's ${ }^{60} \mathrm{Co}$ source. Cells suspended in growth medium were placed in 6-well plates $\left(5 \times 10^{6}\right.$ cells $/ \mathrm{ml} ; 2 \mathrm{ml}$ per well $)$ and exposed to ${ }^{60} \mathrm{Co}$ gamma-radiation at various total doses using a dose rate of $0.6 \mathrm{~Gy} / \mathrm{min}$. Cells were then returned to the incubator in a $5 \% \mathrm{CO}_{2}$ atmosphere at $37{ }^{\circ} \mathrm{C}$ for the specified time. 


\subsubsection{Animals}

For survival experiments, mice ( $\mathrm{n}=16$ per group) received $9.25 \mathrm{~Gy}$ (equivalent to LD90/30) of total-body ${ }^{60} \mathrm{Co}$ gamma-photon radiation administered at a dose rate of $0.6 \mathrm{~Gy} / \mathrm{min}$. Shamtreated mice were handled identically but received no radiation. After treatment, mice were returned to their original cages and survival was monitored for $30 \mathrm{~d}$. Body weight and facial dropsy were assessed. Mean survival times $\left(\mathrm{ST}_{50}\right)$ were observed. The moribund mice found during the observation period were euthanized in accordance with recommendations [39, 40] and guidelines [41]. For mechanistic experiments, mice also received $9.25 \mathrm{~Gy}$ ( $\mathrm{n}=6$ per group). At specified time points after irradiation, mice were euthanized in accordance with recommendations [39,40] and guidelines [41]. Interested tissues were harvested 1 and $7 \mathrm{~d}$ after irradiation and stored at $-80^{\circ} \mathrm{C}$ until use for biochemical assays and western blots. Ileum was also prepared for immunofluorescence assessment.

\subsection{Western blots}

To investigate amounts of caspase- 3 and LC3 proteins, ileum was minced, mixed in $100 \mu \mathrm{L} \mathrm{Na}$ Hanks' solution containing protease inhibitors, sonicated, and centrifuged at $8000 \mathrm{xg}$ for 10 min. The supernatant was collected and total protein was determined with Bio-Rad reagent (Bio-Rad, Richmond, CA, USA). Aliquots containing $20 \mu \mathrm{g}$ of protein in tris buffer ( $\mathrm{pH}=6.8$ ) containing $1 \%$ sodium dodecyl sulfate (SDS) and 1\% 2-mercaptoethanol were resolved on SDSpolyacrylamide slab gels (Novex precast 4-20 \% gel; Invitrogen, Grand Island, NY, USA). After electrophoresis, proteins were blotted onto a PDVF nitrocellulose membrane (type NC, $0.45 \mu \mathrm{m}$; Invitrogen), using a Novex blotting apparatus and the manufacturer's protocol. After blocking the nitrocellulose membrane by incubation in tris-buffered saline- $0.5 \%$ tween20 (TBST) containing 3\% nonfat dried milk for $90 \mathrm{~min}$ at room temperature, the blot was incubated for 60 min at room temperature with monoclonal antibodies directed against caspase-3 and LC3 at a concentration of $1 \mu \mathrm{g} / \mathrm{ml}$ in TBST - 3\% dry milk. The blot was then washed 3 times (10 min each) with TBST before incubating the blot for $60 \mathrm{~min}$ at room temperature with a 1000X dilution of species-specific IgG peroxidase conjugate (Santa Cruz Biotechnology) in TBST. The blot was washed 6 times ( 5 min each) in TBST before detection of peroxidase activity using the Enhanced Chemiluminescence Plus kit (Amersham Life Science Inc., Arlington Heights, IL, USA). IgG levels were not altered by radiation; we therefore used IgG as a control for protein loading. Protein bands of interest were quantitated densitometrically and normalized to IgG.

\subsection{Nitric oxide measurements}

Nitric oxide (NO) production was measured under acidic conditions as nitrite, using a commercial kit (Biomedical Research Service, School of Medicine and Biomedical Sciences, State University of New York at Buffalo, NY, USA; www.bmrservice.com).

\subsection{Lipid peroxidation measurements}

Malondialdehyde (MDA), a lipid peroxidation end product, was measured colorimetrically using a commercial lipid peroxidation assay kit (CalBiochem, San Diego, CA). 


\subsection{Detection and analysis of caspase-3/7 activity by confocal microscopy}

The Magic Red ${ }^{\circledR}$ Caspase Detection kit (MP Biomedicals; Solon, OH, USA) was used for the detection of caspase-3/7 activity, following the manufacturer's protocol. Briefly, about $2 \times 10^{5}$ cells were stained in the presence of up to $300 \mu \mathrm{l}$ of OPTI-MEM I medium (Invitrogen). Cells were seeded onto \#1 borosilicate glass slides with 4-well chambers (Fisher Science Education, Hanover Park, IL). An LSM 5 PASCAL Zeiss laser scanning confocal microscope (Carl Zeiss MicroImaging; Thornwood, NY, USA) with a 100×/1.3 NA Plan Apochromat oil objective was used to scan the signals. Each resulting image was provided with a simultaneous scan of differential interference contrast (DIC).

\subsection{Immunofluorescence staining and image analysis}

Small intestine specimens (5 per each of animal groups) collected at necropsy were processed for the immunofluorescence analysis and analyzed using fluorescence confocal microscopy [42]. Donkey normal serum and antibody were diluted in phosphate buffered saline (PBS) containing 0.5\% BSA and $0.15 \%$ glycine. Any nonspecific binding was blocked by incubating the samples with purified donkey normal serum (Santa Cruz Biotechnology, Inc., Santa Cruz, CA, USA) diluted 1:20. The primary antibodies were raised against CD15 (mouse monoclonal biotin conjugated IgM from eBioscience), MAP LC3and AD4 (vendors indicated above). This was followed by incubation with secondary fluorochrome-conjugated antibody and/or streptavidin-AlexaFluor 610 conjugate (Molecular Probes, Inc., Eugene, OR, USA), and with Heochst 33342 (Molecular Probes) diluted 1:3000. The secondary antibodies used were AlexaFluor 488 and AlexaFluor 594 conjugated donkey IgG (Molecular Probes Inc.) Negative controls for nonspecific binding included normal goat serum without primary antibody or with secondary antibody alone. Five confocal fluorescence and DIC images of crypts (per specimen) were captured with Zeiss LSM 7100 microscope. Immunofluorescence image analysis was conducted as described previously [43]. The index of spatial correlation ( $r$ ) of proteins was determined by multiple pixel analysis for pairwise signal interaction of green and red channels. Paneth cell identification was conducted by i) their spatial localization in crypts; ii) presence of immunoreactivity to CD15 and AD4, which are specific to this epithelial phenotype; iii) spatial appearance of the immunoreactivity to CD15, AD4, and the FISH reactivity to AD4 mRNA (see above) in morphologically identified Paneth cells.

\subsection{Solutions}

$\mathrm{Na}^{+}$Hanks' solution contained in mM: $145 \mathrm{NaCl}, 4.5 \mathrm{KCl}, 1.3 \mathrm{MgCl}_{2}, 1.6 \mathrm{CaCl}_{2}$, and 10 HEPES (pH 7.40 at $24^{\circ} \mathrm{C}$ ). Na+ Hanks' stop buffer contained in mM: 50 tris- $\mathrm{HCl}, 1 \% \mathrm{NP}-40,0$ $.25 \% \mathrm{Na}^{+}$-deoxycholate, $150 \mathrm{NaCl}, 1$ EDTA, 1 phenylmethanesulfonyl fluoride, $1 \mathrm{Na}^{\mathrm{VO}} \mathrm{V}_{4}, 1$ $\mathrm{NaF}$, along with aprotinin, leupeptin, and pepstatin $\left(10 \mu \mathrm{g} / \mathrm{mL}\right.$ each). $\mathrm{Na}^{+}$Hanks' wash buffer contained in mM: 1 EDTA, 1 phenylmethanesulfonyl fluoride, 1 DTT, $1 \mathrm{Na}_{3} \mathrm{VO}_{4}, 1$ $\mathrm{NaF}$, along with aprotinin, leupeptin, and pepstatin $(10 \mu \mathrm{g} / \mathrm{mL}$ each). 


\subsection{Statistical analysis}

Results represent the mean \pm s.e.m. One-way ANOVA, Studentized-range test, Bonferroni's inequality, and Student's t-test were used for comparison of groups with $5 \%$ as a significant level.

\section{Response of human $\mathrm{T}$ cells to irradiation}

\subsection{Gamma radiation increased lipid peroxidation production}

Cells were irradiated with 2, 4, 6, or $8 \mathrm{~Gy}$; the lipid peroxidation marker MDA was measured in these cells at 4, 24, 48, and $72 \mathrm{~h}$ postirradiation. Figure 1 shows MDA levels increased in a radiation dose- and postirradiation time-dependent manner in cells receiving 2, 4, and 6 Gy (Fig. 1A-C). Cells receiving 8 Gy (Fig. 1D) had lipid peroxidation levels above the baseline at all times tested. But in cells receiving $6 \mathrm{~Gy}$ and $8 \mathrm{~Gy}$, by $24 \mathrm{~h}$ postirradiation the levels were significantly lower than those observed in cells receiving 4 Gy (Fig. 1C vs. 1B and Fig. 1D vs. 1B). This observation may be a reflection of the drop in cell viability previously observed in cells after doses greater than $4 \mathrm{~Gy}$.

A. 2 Gy

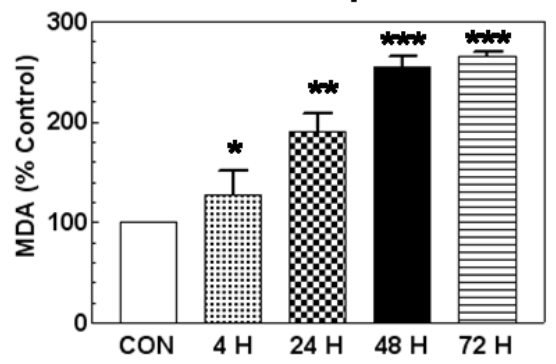

C. $6 \mathrm{~Gy}$

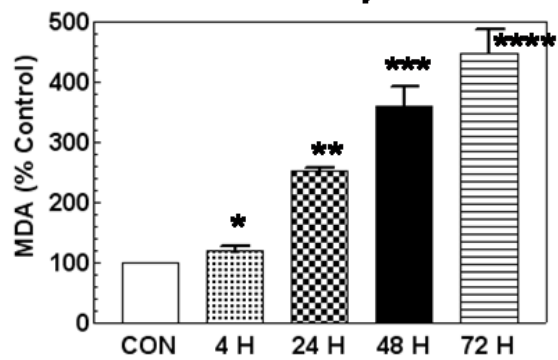

B. 4 Gy

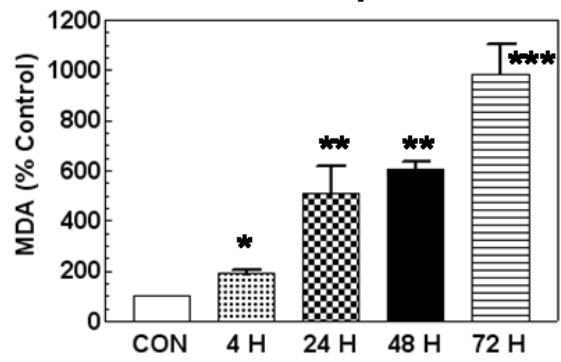

D. 8 Gy

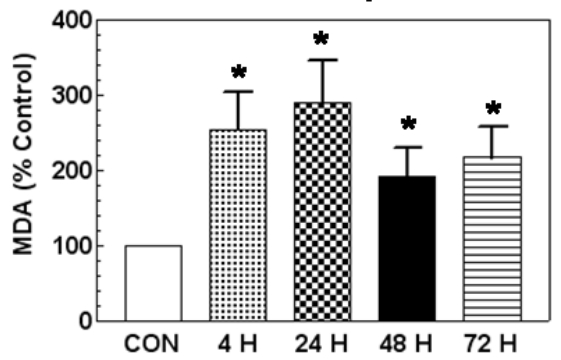

Jurkat $T$ cells were exposed to gamma radiation at 2 (A), 4 (B), 6 (C), or 8 Gy (D) and allowed to respond for 4, 24, 48, or 72 $\mathrm{h}(\mathrm{n}=3)$ before preparation of cell lysates. Lipid peroxidation as indicated by MDA was measured. Data are expressed relative to that of unirradiated controls. For panels $\mathrm{A}$ : ${ }^{*} \mathrm{P}<0.05 \mathrm{vs}$. control, $24 \mathrm{H}, 48 \mathrm{H}$, and $72 \mathrm{H}$; ${ }^{* *} \mathrm{P}<0.05 \mathrm{vs}$. control, $4 \mathrm{H}, 48$ $\mathrm{H}$, and $72 \mathrm{H} ;{ }^{* * *} \mathrm{P}<0.05$ vs. control, $4 \mathrm{H}$, and $24 \mathrm{H}$. For Panel B: ${ }^{*} \mathrm{P}<0.05$ vs. control, $24 \mathrm{H}, 48 \mathrm{H}$, and $72 \mathrm{H}$; ${ }^{* *} \mathrm{P}<0.05$ vs. control, $4 \mathrm{H}$, and $72 \mathrm{H}$; ${ }^{* * *} \mathrm{P}<0.05$ vs. control, $4 \mathrm{H}, 24 \mathrm{H}$, and $48 \mathrm{H}$. For panels $\mathrm{C}$ : ${ }^{*} \mathrm{P}<0.05$ vs. control, $24 \mathrm{H}, 48 \mathrm{H}$, and $72 \mathrm{H}$; ${ }^{* *} \mathrm{P}<0.05$ vs. control, $4 \mathrm{H}, 48 \mathrm{H}$, and $72 \mathrm{H}$; ${ }^{* * *} \mathrm{P}<0.05$ vs. control, $4 \mathrm{H}, 24 \mathrm{H}$, and $72 \mathrm{H}$; ${ }^{* * * *} \mathrm{P}<0.05$ vs. control, $4 \mathrm{H}, 24 \mathrm{H}$, and $48 \mathrm{H}$. For panel D: ${ }^{*} \mathrm{P}<0.05$ vs. control, determined by one way ANOVA and studentized-range test. CON: unirradiated controls

Figure 1. Gamma radiation increased lipid peroxidation in T cells. 


\subsection{Gamma radiation increased NO production}

Because $\mathrm{NO}$ is known to react with $\mathrm{O}_{2}$ - to form peroxynitrite (ONOO-) that can oncrease lipid peroxidation [23], we measured NO production levels in irradiated Jurkat cells. Figure 2 shows NO production in irradiated cells. By $4 \mathrm{~h}$ postirradiation cells receiving 2, 4, or $6 \mathrm{~Gy}$ showed NO levels statistically lower than non-irradiated controls, but cells receiving $8 \mathrm{~Gy}$ showed an increase. By 24 and $48 \mathrm{~h}$, all irradiated cells exhibited increased NO production, generally in a radiation dose-dependent manner. By $72 \mathrm{~h}$ postirradiation NO level returned to baseline in cells receiving 4, or $8 \mathrm{~Gy}$, while NO levels in cells receiving 2 or 6 Gy remained above the baseline and had dropped below baseline, respectively.

A. 2 Gy

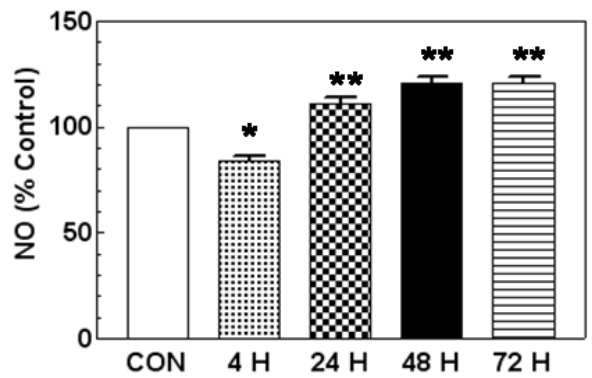

C. 6 Gy

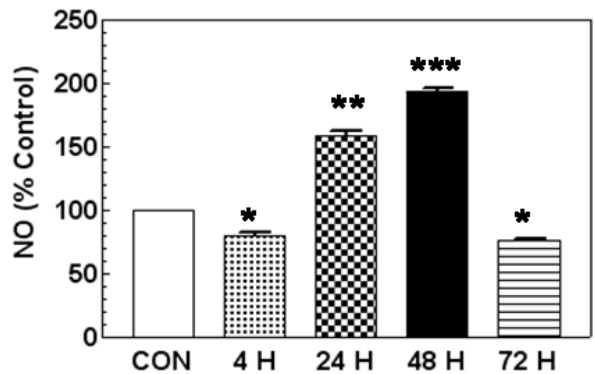

B. 4 Gy

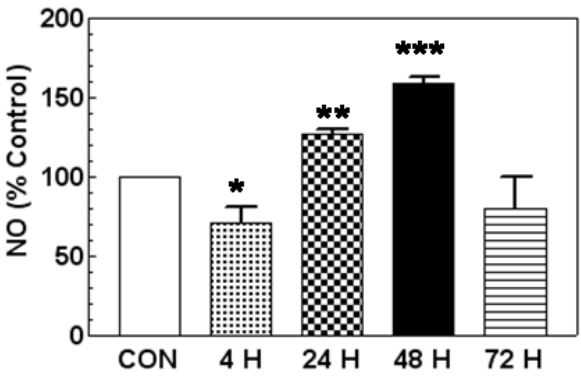

D. 8 Gy

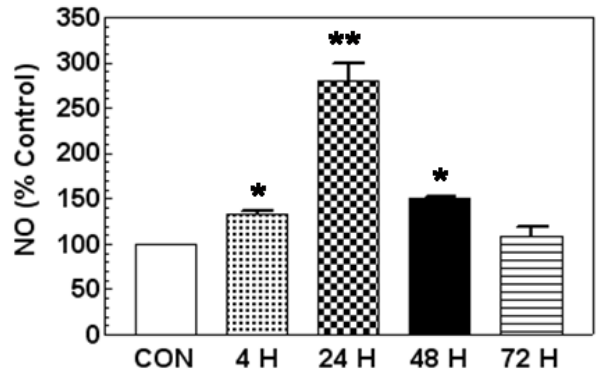

Jurkat T cells were exposed to gamma radiation at 2 (A), 4 (B), 6 (C), or 8 Gy (D) and allowed to respond for 4, 24, 48, or $72 \mathrm{~h}(\mathrm{n}=3)$ before preparation of cell lysates. NO production was measured. Data are expressed relative to that of unirradiated controls. For panel A: ${ }^{*} \mathrm{P}<0.05$ vs. control, $24 \mathrm{H}, 48 \mathrm{H}$, and $72 \mathrm{H}$; ${ }^{* *} \mathrm{P}<0.05$ vs. control and $4 \mathrm{H}$. For Panel B: ${ }^{*} \mathrm{P}<0.05$ vs. control, $24 \mathrm{H}$, and $48 \mathrm{H}$; ${ }^{* *} \mathrm{P}<0.05$ vs. control, $4 \mathrm{H}, 48 \mathrm{H}$, and $72 \mathrm{H}$; ${ }^{* * *} \mathrm{P}<0.05$ vs. control, $4 \mathrm{H}, 24 \mathrm{H}$, and $72 \mathrm{H}$.

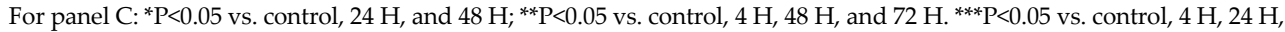
and $72 \mathrm{H}$. For panel $\mathrm{D}$ : ${ }^{*} \mathrm{P}<0.05$ vs. control, $24 \mathrm{H}$, and $72 \mathrm{H}$; ${ }^{* *} \mathrm{P}<0.05$ vs. control, $4 \mathrm{H}, 48 \mathrm{H}$, and $72 \mathrm{H}$, determined by one way ANOVA and studentized-range test. $\mathrm{CON}$ : unirradiated controls

Figure 2. Gamma radiation increased NO production in T cells.

\subsection{Gamma radiation increased apoptosis}

Lipid peroxidation occurring within the cell and mitochondrial membranes can trigger apoptosis [28]. Because increased caspase-3 and -7 are indicators of cells undergoing 
apoptosis [16-18], we measured caspase-3 and -7 in irradiated Jurkat cells. As shown in Fig. 3 , cells receiving 8 Gy displayed significantly increased immunofluorescence of caspase-3/-7, compared to non-irradiated cells. The percentages of non-irradiated cells and irradiated cells presenting the caspase-3/-7 immunofluorescence were 23 and $85 \%$, respectively, suggesting that gamma irradiation increases apoptosis.

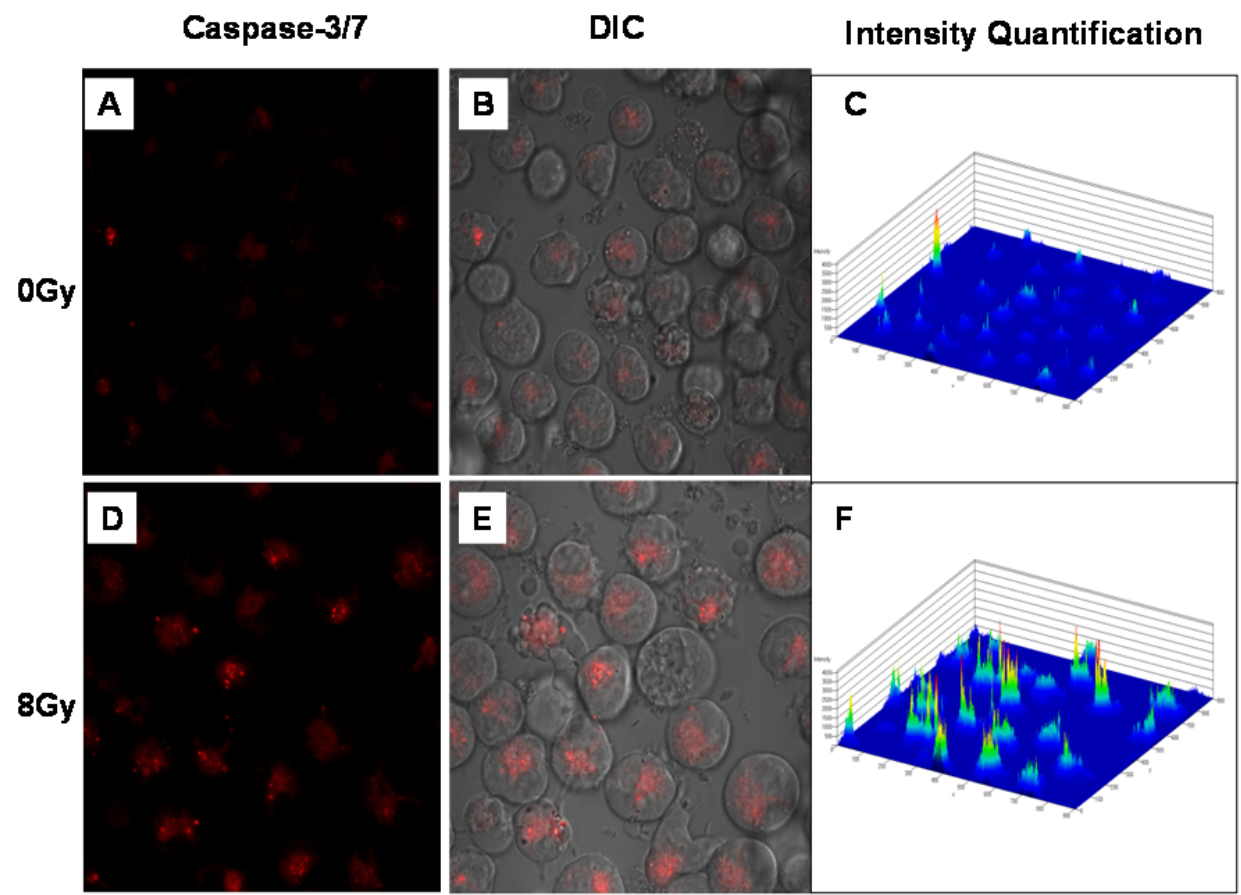

Freshly isolated human Jurkat T cells were counted, seeded, and allowed to grow for $24 \mathrm{~h}$. Cells were then irradiated at $8 \mathrm{~Gy}$ and returned to incubator. Live cells were studied $24 \mathrm{~h}$ postirradiation for internal caspase-3/7 activities by Magic Red ${ }^{\circledR}$ staining.

Figure 3. Gamma radiation increased apoptosis in $\mathrm{T}$ cells.

\section{Response of mice to irradiation}

The organs most sensitive to radiation are the hematopoietic, lymphoid, gastrointestinal, reproductive, vascular, and cutaneous systems [44]. We used mice irradiated with $9.25 \mathrm{~Gy}$ ${ }^{60} \mathrm{Co}$-gamma photons to determine if events similar to those observed in vitro also occurred in vivo. Thirty-day survival, body weight, facial dropsy, and ileum were also assessed.

\subsection{Gamma radiation decreased mouse survival and body weight}

Irradiated mice first demonstrated mortality $9 \mathrm{~d}$ after irradiation and showed no survival 23 $\mathrm{d}$ after irradiation. The mean survival time (ST50) was $12 \mathrm{~d}$. All non-irradiated mice survived 
(Fig. 4A). Irradiated mice demonstrated significant body weight loss $10 \mathrm{~d}$ after irradiation and lost over $20 \%$ by the end of the experiment; non-irradiated mice gained weight daily. The rate of weight change was $-0.6 \mathrm{~g} / \mathrm{d}$ for irradiated mice and $0.17 \mathrm{~g} / \mathrm{d}$ for non-irradiated mice. The observations are in agreement with those obtained in previous experiments using irradiated B6D2F1/J mice [45]

A

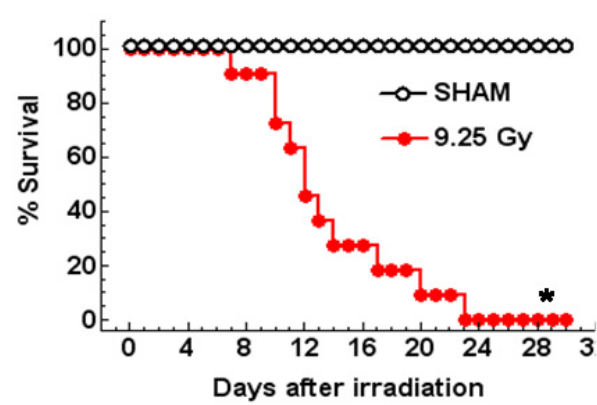

B

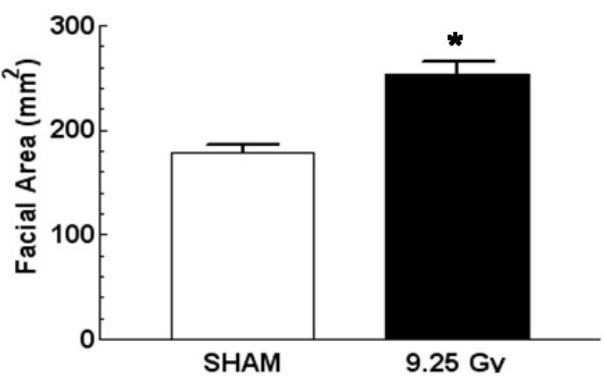

Mice ( $\mathrm{n}=16$ per group) received $9.25 \mathrm{~Gy}$. (A) Radiation significantly reduced $30-\mathrm{d}$ survival after irradiation. ${ }^{*} \mathrm{P}<0.01 \mathrm{vs}$. sham group, determined by one-way ANOVA and Student's t-test. (B) Radiation induced facial dropsy. Facial dropsy was assessed by measuring increase in facial area. Facial area was approximated by multiplying width between outer edges of ears and distance from ear-to-ear midpoint to tip of snout and then dividing by 2 (area of a triangle). Facial dropsy in each mouse was calculated approximately $10 \mathrm{~d}$ after $9.25 \mathrm{~Gy}$ (9-12 d, point of maximal swelling) and averaged. ${ }^{*} \mathrm{P}<0.05 \mathrm{vs}$. sham group, determined by Student's t-test.

Figure 4. Gamma radiation decreased survival and increased facial dropsy.

\subsection{Gamma radiation induced facial dropsy}

Irradiated mice began to show facial dropsy around $10 \mathrm{~d}$ postirradiation (Fig. 4B). The overall increase in dropsy was approximately $43 \%$. Facial dropsy did not occur in previous experiments using irradiated B6D2F1/J mice [44] or in humans [46], suggesting the response is mouse strain- and species-specific.

\subsection{Gamma radiation induced lipid peroxidation and NO production}

Ileum lysate was obtained for MDA measurement from mice exposed to $9.25 \mathrm{~Gy}$. As shown in Fig. 5, irradiation increased MDA levels (Fig. 5A) and NO production (Fig. 5B). The results were consistent with in vitro findings using human $\mathrm{T}$ cells.

\subsection{Gamma radiation induced increases in caspase-3 and LC3}

To measure apoptosis in ileum from irradiated mice, we performed an immunoblot analysis of ileum caspase-3, a biomarker for apoptosis [29-31]. Radiation induced an approximate 2.5-fold increase in caspase-3 (Fig. 6A-B). The result was consistent with the in vitro findings with Human T cells. 
To measure autophagy in ileum from irradiated mice, we performed an immunoblot analysis of ileum LC3 protein, a biomarker for Autophagy [13]. Radiation induced an approximate 3.5-fold increase in LC3 (Fig. 6A and C).

A

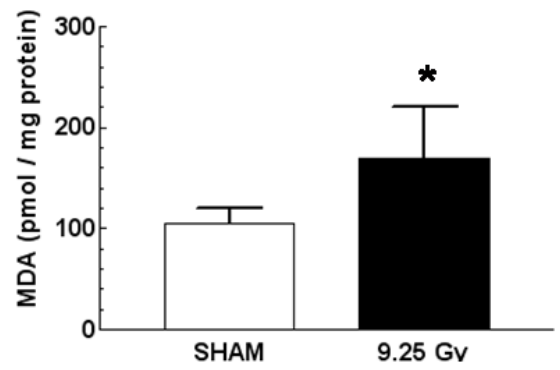

B

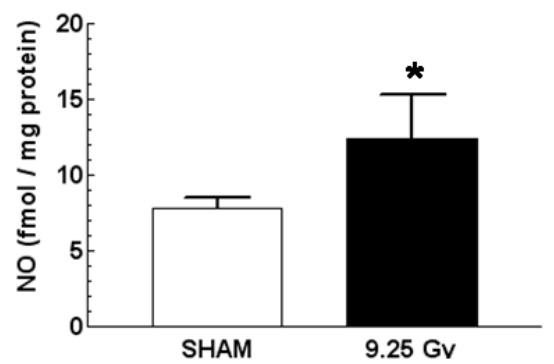

Mice ( $n=6$ per group) received 9.25 Gy. Ileum tissues were collected $1 \mathrm{~d}$ postirradiation and cell lysates prepared. (A) Lipid peroxidation as indicated by MDA was measured. (B) NO production was measured. ${ }^{*} \mathrm{P}<0.05$ vs. sham group, determined by Student's t-test.

Figure 5. Gamma increased lipid peroxidation and NO production in ileum.

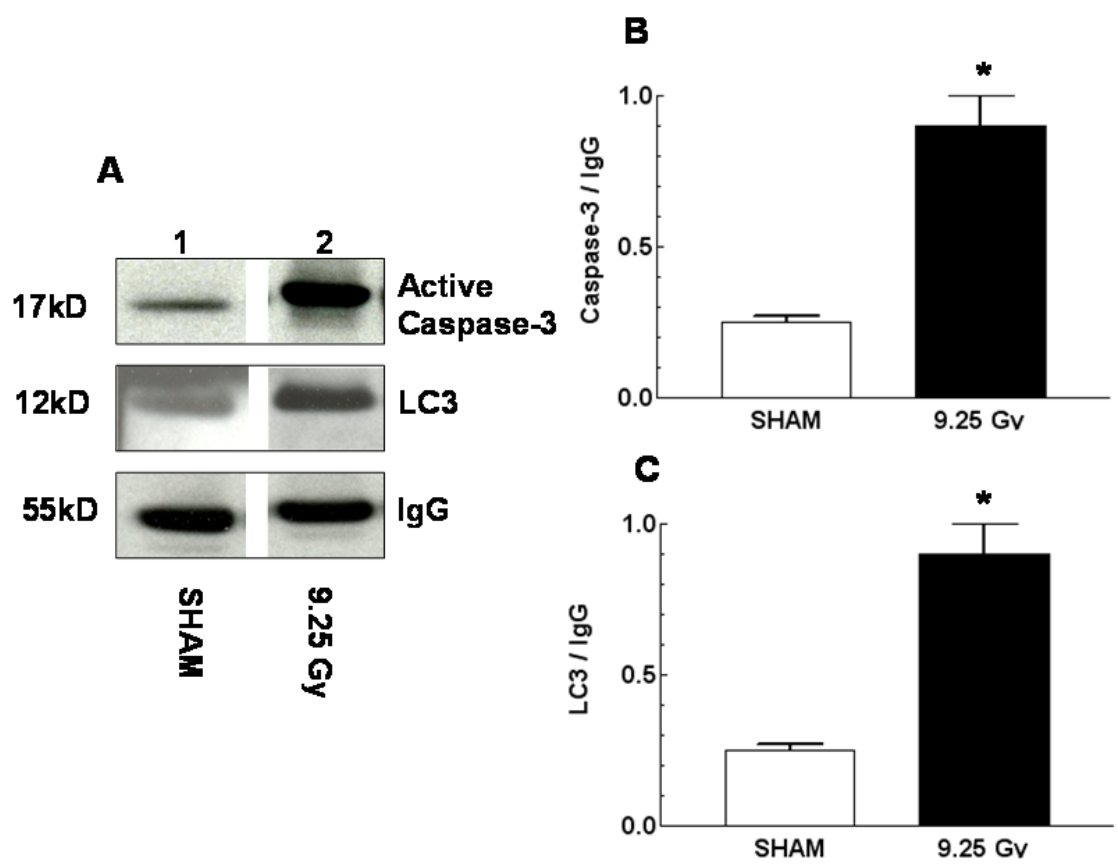

Mice ( $\mathrm{n}=6$ per group) received $9.25 \mathrm{~Gy}$. Ileum tissues were collected $1 \mathrm{~d}$ postirradiation and cell lysates prepared. (A) Representative Western blots. (B) Caspase-3 and LC3 were quantitated densitometrically and normalized to IgG. ${ }^{*} \mathrm{P}<0.05$ vs. sham, determined by Student's t-test.

Figure 6. Gamma radiation increased caspase-3 and LC3 in ileum. 


\subsection{Gamma radiation induced apoptosis in mouse ileal villi}

The immunofluoresence images in Fig. 7 show that there was little immunofluorescence present in ileal villi of non-irradiated mice (Fig. A and C), whereas there was a significant increase in immunofluorescence in ileal villi of irradiated mice (Fig. B and D). It is known that ileal epithelial cells regularly slough off after undergoing apoptosis and are then replenished within $7 \mathrm{~d}$ [47]. It is not clear if irradiation accelerated the rate of apoptosis, but ionizing radiation-induced increases in apoptosis were observed in these studies (Fig. B vs. A). Similar results were observed in earlier studies using irradiated B6D2F1/J mice [48].
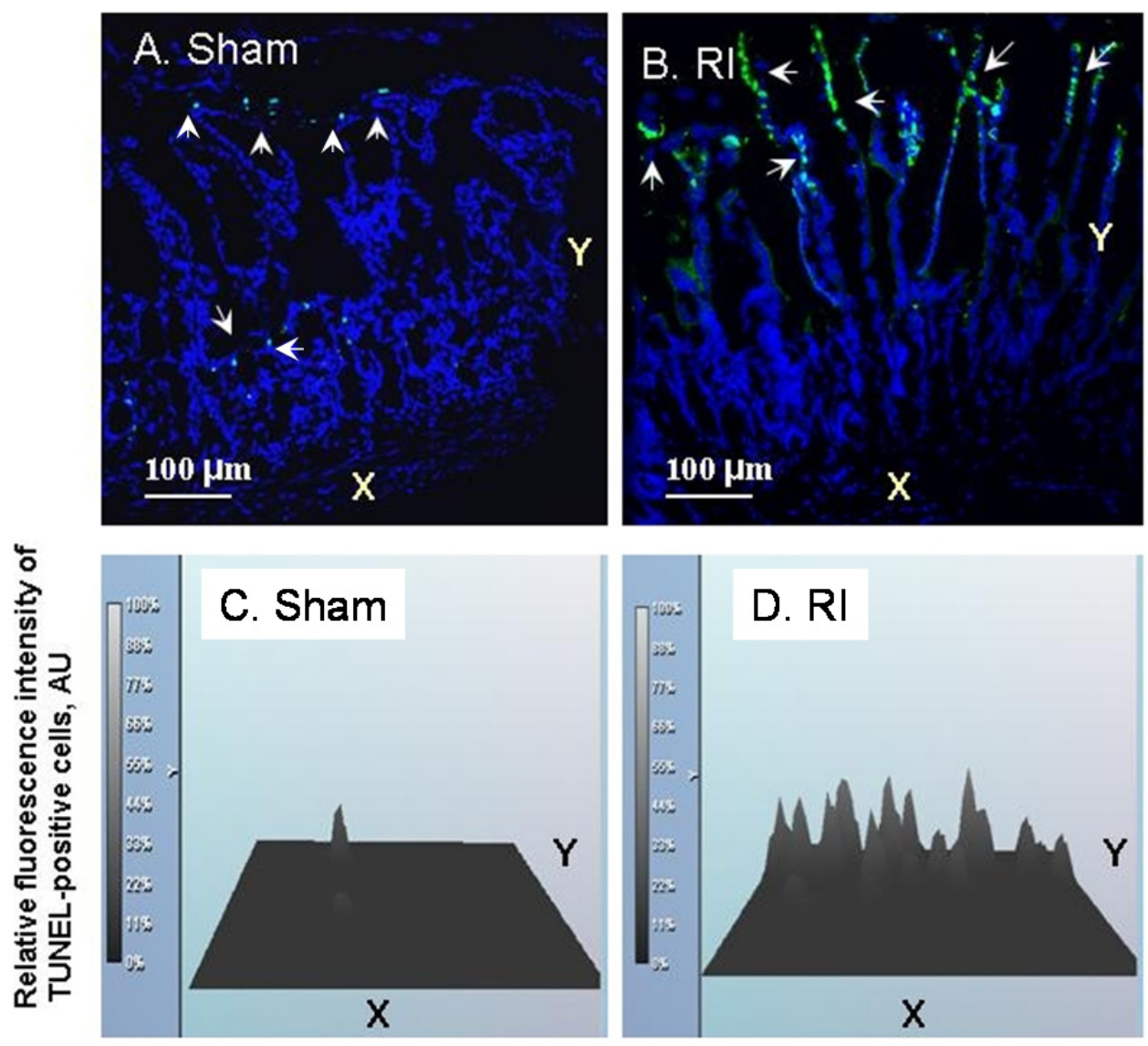

\section{TUNEL - Green; Nuclei - Blue}

Mice ( $n=6$ per group) received 9.25 Gy. Ileum tissues were collected $7 \mathrm{~d}$ postirradiation and slide preparations were stained using TUNEL assay to detect apoptosis. (A-B) Confocal microscopy fluorescent images: green fluorescence indicates apoptotic cells; blue Hoechst 33342 fluorescence indicates all nuclei. (C-D) Quantitation of fluorescence intensities.

Figure 7. Gamma radiation induced apoptosis in ileum. 


\subsection{Gamma radiation induced autophagy in mouse ileal crypts}

In ileum, stem cells anchored in the crypts gives rise to proliferating progenitor cells that exit the cell cycle as they migrate and differentiate into 4 different cell types, including enterocytes, goblet cells, enteroendocrine cells, and Paneth cells [see reviews 49, 50]. Paneth cells produce defensins to protect against bacterial entry via the gut barrier $[49,50]$. However, stem cells have also been shown to inhibit bacterial entry [51]. The immunofluoresence images in Fig. 8 show that there was little immunofluorescence present in ileal crypts of non-irradiated mice (A and C), whereas there was significant increase in immunofluorescence in ileal crypts of irradiated mice (B and D). Autophagy occurred in both stem cells and Paneth cells (using CD-15 as a biomarker). Ionizing radiation-induced increases in autophagy (B vs. A) have also been observed in B6D2F1/J mice [44].

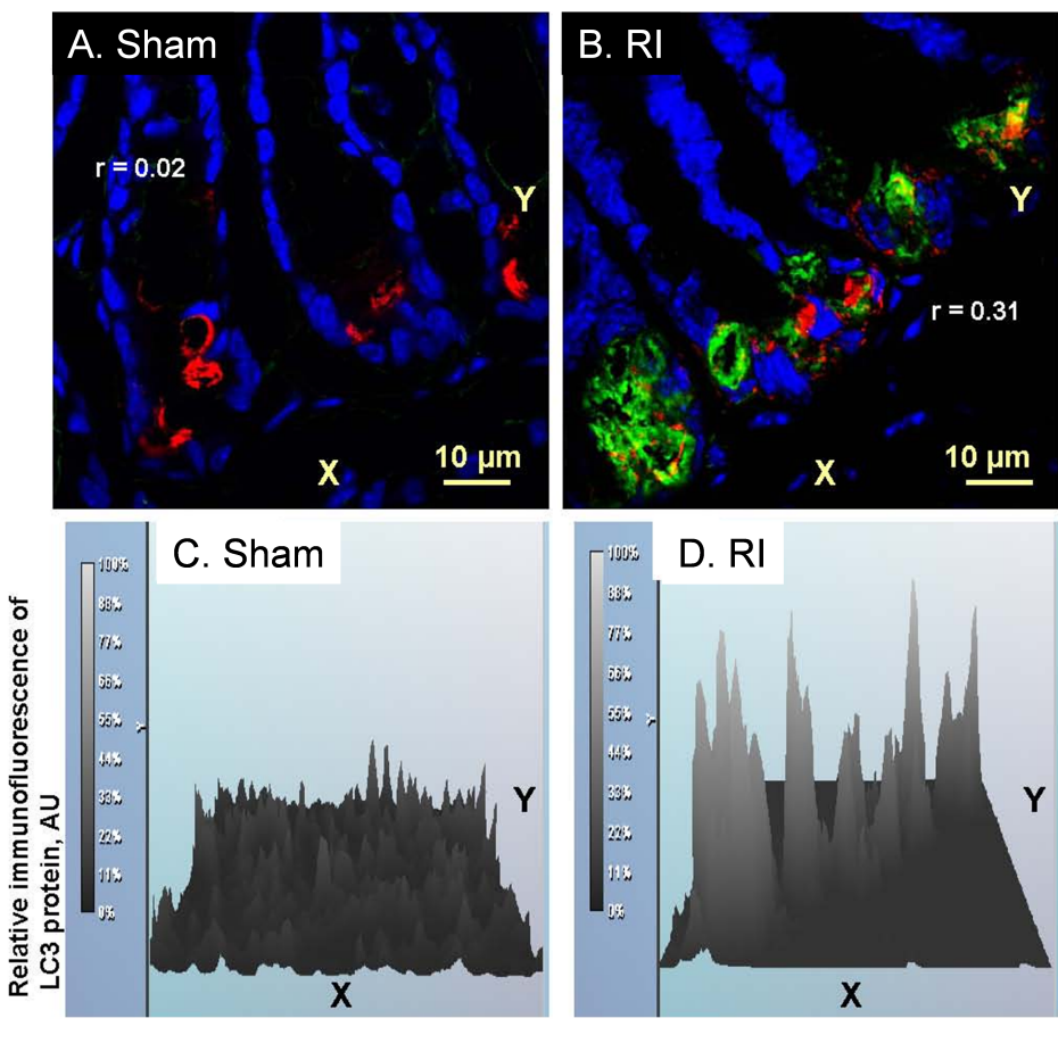

Paneth cells - Red; LC3 - Green; Nuclei - Blue

Mice ( $\mathrm{n}=6$ per group) received $9.25 \mathrm{~Gy}$ irradiation. Ileum tissues were collected $7 \mathrm{~d}$ postirradiation and slide preparations were stained with anti-LC3 antibody to detect autophagy indicator LC-3. (A-B) Confocal microscopy fluorescent images: green fluorescence indicates anti-LC3 antibody; blue Hoechst 33342 fluorescence indicates all nuclei. (C-D) Quantitation of fluorescence intensities.

Figure 8. Gamma radiation induced autophagy in ileum. 


\section{Conclusion}

The complexity of the cellular response to ionizing radiation complicates efforts to design approaches to treat or prevent injury resulting from ionizing radiation. Ionizing radiation activates many signal transduction pathways [44, 52], including the one involving lipid peroxidation. It is known that $\mathrm{Bcl}-2$ (an anti-apoptotic protein) decreases lipid peroxidation [53]. Although in cultured cells, silencing of the iNOS gene by iNOS siRNA inhibits lipid peroxidation and the subsequent production of apoptosis-related proteins [12], ionizing radiation increases lipid peroxidation even in iNOS knockout mice (Lu and Kiang, unpublished data). This suggests that radiation-induced activation of iNOS pathway is not all for its occurrence. Nevertheless, total body ionizing irradiation causes lipid peroxidation, caspase-3 activation, LC3 increases, and apoptosis and autophagy in ileum, suggesting the ileal cell death may contribute to ionizing radiation-induced mortality and body weight loss (Fig. 4). The mechanism underlying radiationinduced facial dropsy is unclear and warrants further investigation.

Figure 9 shows a schematic representation of lipid peroxidation-mediated induction of apoptosis and autophagy after exposure to gamma-radiation. Mitochondrial membrane lipid peroxidation is induced either directly by radiation or indirectly by increased NO production as a result of radiation-induced iNOS upregulation. Lipid peroxidation in the mitochondrial membrane leads to release of cytochrome $\mathrm{c}$ into the cytoplasm. Cytochrome c complexes with Apf- 1 and seven molecules of caspase- 9 to form an apoptosome. Apoptosomes then activate caspase- 3 and -7 . Active caspase- 3 subsequently activates other caspases in the cytoplasm, which leads to apoptosis. It is not known what role plasma membrane lipid peroxidation plays in the apoptosis and autophagy processes. Lipid peroxidation also increases LC3 to cause autophagy, a process whose poorly understood molecular mechanisms warrant further investigation.

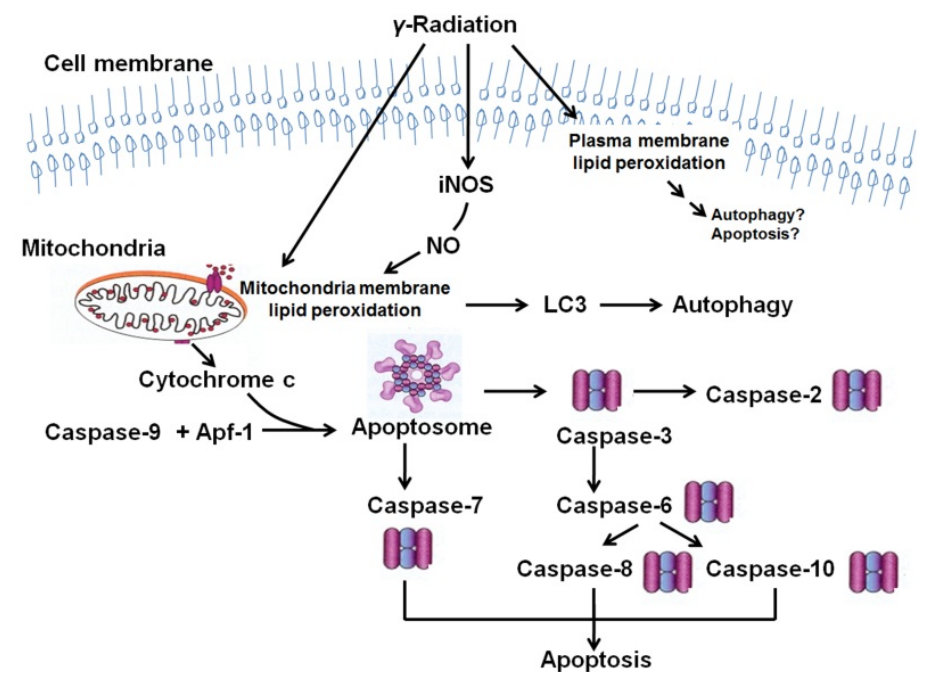

Figure 9. Schematic representation of lipid peroxidation-mediated induction of apoptosis and autophagy after exposure to gamma-radiation. iNOS: inducible nitric oxide synthase; NO: nitric oxide; LC3: light chain 3; Apf-1: ATP-dependent proteolysis factor 1 


\section{Perspective}

Cell death resulting from ionizing radiation is a common scenario in the clinical practice of medicine and probably occurs in virtually all organ systems. Its hallmarks are relatively consistent across species and probably organ systems. Blockade of lipid peroxidation could be a useful approach to prevent radiation injury. In the murine model [14, 17-19, 21], radiation-induced lipid peroxidation occurs in fetal brain cultures [14], liver [17-19], and serum [21] as well as in the ileum, as reported in this chapter. A wide range of agents has been shown to effectively inhibit radiation-induced lipid peroxidation, including $\mathrm{N}$ acetylcysteine [15], melatonin [16], vitamin E [20, 22], MnSOD-Plasmid Liposomes [14], leaf extract of Moringa oleifera [17], cinnamon extract [18], green tea polyphenol [21], hesperidin [19], and 17-DMAG [Lu and Kiang, unpublished data]. Since the response to radiation involves many signal transduction pathways, a combination of drugs targeting different signaling pathways may be a useful approach to address the difficult problem of protecting from ionizing radiation injury.

\section{Author details}

Juliann G. Kiang*, Risaku Fukumoto and Nikolai V. Gorbunov

Radiation Combined Injury Program, Armed Forces Radiobiology Research Institute,

Uniformed Services University of the Health Sciences, Bethesda, Maryland,

USA

\section{Acknowledgement}

The authors thank HM1 Neil Agravante and Ms. Joan T. Smith for their technical support and Dr. David E. McClain for his scientific discussion and editorial assistance.

\section{Grants}

This work was supported by AFRRI Intramural RAB2CF (to JGK) and DTRA CBM.RAD.01.10.AR.010 (to JGK). There are no ethical and financial conflicts in the presented work.

\section{Disclaimer}

The opinions or assertions contained herein are the authors' private views and are not to be construed as official or reflecting the views of the United States Department of Defense.

\section{References}

[1] Jay A, LaVerne JA. OH Radicals and Oxidizing Products in the Gamma Radiolysis of Water. Radiation Research. 2000; 153:196-200.

${ }^{*}$ Corresponding Author 
[2] Nakagawa K, Nishio T. Electron paramagnetic resonance investigation of sucrose irradiated with heavy ions. Radiat Res. 2000; 153:835-9.

[3] Nauser T, Koppenol WH, Gebicki JM. The kinetics of oxidation of GSH by protein radicals. Biochem J. 2005; 392(Pt 3):693-701.

[4] Gebicki JM, Nauser T, Domazou A, Steinmann D, Bounds PL, Koppenol WH. Reduction of protein radicals by GSH and ascorbate: potential biological significance. Amino Acids. 2010; 39:1131-7.

[5] Østdal H, Davies MJ, Andersen HJ. Reaction between protein radicals and other biomolecules. Free Radic Biol Med. 2002; 33:201-9.

[6] Tappel AL. Vitamin E and selenium protection from in vivo lipid peroxidation. Ann N Y Acad Sci. 1980; 355:18-31.

[7] Davies MJ, Forni LG, Willson RL. Vitamin E analogue Trolox C. E.s.r. and pulseradiolysis studies of free-radical reactions. Biochem J. 1988; 255:513-22.

[8] Bild W, Ciobica A, Padurariu M, Bild V. The interdependence of the reactive species of oxygen, nitrogen, and carbon. J Physiol Biochem. 2012 Mar 29. [Epub ahead of print]

[9] Azzam EI, Jay-Gerin JP, Pain D. Ionizing radiation-induced metabolic oxidative stress and prolonged cell injury. Cancer Lett. 2011 Dec 17. [Epub ahead of print]

[10]. Leach JK, Van Tuyle G, Lin PS, Schmidt-Ullrich R, Mikkelsen RB. Ionizing radiationinduced, mitochondria-dependent generation of reactive oxygen/nitrogen. Cancer Res. 2001; 61:3894-901.

[11] Tyurina YY, Tyurin VA, Epperly MW, Greenberger JS, Kagan VE. Oxidative lipidomics of gamma-irradiation-induced intestinal injury. Free Radic Biol Med. 2008; 44:299-314.

[12] Kiang JG, Smith JA, and Agravante NG. Geldanamycin analog 17-DMAG inhibits iNOS and caspases in gamma irradiated human T cells. Radiat Res. 2009; 172: 321-30.

[13] Gorbunov NV, Kiang JG. Up-regulation of Autophagy in the Small Intestine Paneth Cell in Response to Total-Body $\gamma$-Irradiation. J Pathol. 2009; 219: 242-52.

[14] Bernard ME, Kim H, Rwigema JC, Epperly MW, Kelley EE, Murdoch GH, Dixon T, Wang $\mathrm{H}$, Greenberger JS. Role of the esophageal vagus neural pathway in ionizing irradiation-induced seizures in nitric oxide synthase-1 homologous recombinant negative NOS1-/- mice. In Vivo. 2011; 25:861-9.

[15] Mansour HH, Hafez HF, Fahmy NM, Hanafi N. Protective effect of N-acetylcysteine against radiation induced DNA damage and hepatic toxicity in rats. Biochem Pharmacol. 2008; 75:773-89.

[16] El-Missiry MA, Fayed TA, El-Sawy MR, El-Sayed AA. Ameliorative effect of melatonin against gamma-irradiation-induced oxidative stress and tissue injury. Ecotoxicol Environ Saf. 2007; 66:278-86.

[17] Sinha M, Das DK, Bhattacharjee S, Majumdar S, Dey S. Leaf extract of Moringa oleifera prevents ionizing radition-induced oxidative stress in mice. J Med Food. 2011; 14:1167-72.

[18] Azab KSh, Mostafa AH, Ali EM, Abdel-Aziz MA. Cinnamon extract ameliorates ionizing radiation-induced cellular injury in rats. Ecotoxicol Environ Saf. 2011; 74:2324-9.

[19] Kalpana KB, Devipriya N, Srinivasan M, Vishwanathan P, Thayalan K, Menon VP. Evaluating the radioprotective effect of hesperidin in the liver of Swiss albino mice. Eur J Pharmacol. 2011; 658:206-12. 
[20] Karslioglu I, Ertekin MV, Kocer I. Protective role of intramuscularly administered vitamin $\mathrm{E}$ on the levels of lipid peroxidation and the activities of antioxidant enzymes in the lens of rats made cataractous with gamma radiation. Eur J Ophthalmol. 2004; 14:478-95.

[21] Hu Y, Guo DH, Liu P, Cao JJ, Wang YP, Yin J, Zhu Y, Rahman K. Bioactive components from the tea polyphenols influence on endogenous antioxidant defense system and modulate inflammatory cytokines after total-body irradiation in mice. Phytomedicine. 2011; 18:970-5.

[22] Yilmaz S, Yilmaz E. Effects of melatonin and vitamin E on oxidative-antioxidative status in rats exposed to irradiation. Toxicology 2006; 222:1-7.

[23] Zhou X, Taghizadeh K, Dedon PC. Chemical and biological evidence for base propenals as the major source of the endogenous M1dG adduct in cellular DNA. J Biol Chem 2005; 280:25377-82.

[24] Bentzen SM. Preventing or reducing late side effects of radiation therapy: radiobiology meets molecular pathology. Nat Rev Cancer. 2006; 6:702-13.

[25] Buonanno M, de Toledo SM, Pain D, Azzam EI. Long-term consequence of radiationinduced bystander effects depend on radiation quality and dose and correlate with oxidative stress. Radiat Res. 2011; 175:405-15.

[26] Marnett LJ. Lipid peroxidation-DNA damage by malondialdehyde. Mutation Research. 1999; 424:83-95.

[27] Muller FL, Lustgarten M S, Jang Y, Richardson A, Van Remmen H. Trends in oxidative aging theories. Free Radic Biol Med. 2007; 43:477-503.

[28] Choi AO, Cho SJ, Desbarats J, Lovrić J, Maysinger D.Quantum dot-induced cell death involves Fas upregulation and lipid peroxidation in human neuroblastoma cells. J Nanobiotechnology. 2007; 5:1.

[29] Hill MM, Adrain C, Martin SJ. Portrait of a killer: The mitochondrial apoptosome emerges from the shadow. Mol Interventions. 2003; 3:19-25.

[30] Jiang X, Wang X. Cytochrome-c-mediated apoptosis. Annu Rev biochem. 2004; 73:87-106.

[31] Kiang JG, Tsen KT. Biology of hypoxia. Chin J Physiol. 2006; 49:223-33.

[32] Mizushima N, Levine B, Cuervo AM, Klionsky DJ. Autophagy fights disease through cellular self-digestion. Nature. 2008; 451:1069-75.

[33] Yang Z, Klionsky DJ. Eaten alive: a history of macroautophagy. Nat Cell Biol. 2010; 12:814-22.

[34] Klionsky DJ. The Autophagy Connection. Dev Cell. Author manuscript; available in PMC 2011 July 20.

[35] Tooze SA, Yoshimori T. The origin of the autophagosomal membrane. Nat Cell Biol. 2010; 12:831-5.

[36] Weidberg H, Shvets E, Elazar Z. Biogenesis and cargo selectivity of autophagosomes. Annu Rev Biochem. 2011; 80:125-56.

[37] Eskelinen EL. New insights into the mechanisms of macroautophagy in mammalian cells. Int Rev Cell Mol Biol. 2008; 266:207-47.

[38] Sridhar S, Botbol Y, Macian F, Cuervo AM. Autophagy and Disease: always two sidesto a problem. J Pathol. 2011 Oct 12. doi: 10.1002/path.3025. [Epub ahead of print] 
[39] Montgomery CA. Oncologic and toxicologic research: Alleviation and control of pain and distress in laboratory animals. Cancer Bulletin. 1990; 42:230-37.

[40] Tomasivic SP, Coghlan LG, Gray KN, Mastromarino AJ, Travis EL. IACUC evaluation of experiments requiring death as an end point: A cancer center's recommendations. Lab Animal January/February, 31-34 (1988).

[41] American Veterinary Medical Association, Report of the AVMA Panel on Euthanasia. J Am Veterinary Medical Association. 2001; 218:669-96.

[42] Müller CA, Autenrieth IB, Peschel A. Innate defenses of the intestinal epithelial barrier. Cell Mol Life Sci. 2005; 62:1297-307.

[43] Gorbunov NV, Garrison BR, Kiang JG. Response of crypt Paneth cells in the small intestine following total-body gamma-irradiation. Int J Immunopathol Pharmacol. 2010; 23:1111-23.

[44] Kiang JG, Garrison BR, Gorbunov NV. Radiation combined injury: DNA damage, apoptosis, and autophagy. Adapt Med. 2010; 2:1-10.

[45] Kiang JG, Garrison BR, Burns TM, Zhai M, Fukumoto R, Cary LH, Elliott TB, Ledney GD. Radiation combined injury complicates biodosimetric assessment. Radiat Res. 2012; In review.

[46] http://en.wikipedia.org/wiki/Poisoning_of_Alexander_Litvinenko.

[47] AFRRI Handbook. 2009 QuickSeries Publishing, Canada.

[48] Kiang JG, Jiao W, Cary L, Mog SR, Elliott TB, Pellmar TC, Ledney GD. Wound trauma increases radiation-induced mortality by increasing iNOS, cytokine concentrations, and bacterial infections. Radiate Res. 2010; 173: 319-332.

[49] Haegebarth A, Clevers H. Wnt signaling, lgr5, and stem cells in the intestine and skin. Am J Pathol. 2009; 174:715-21.

[50] Van der Flier LG, Clevers H. Stem cells, self-renewal, and differentiation in the intestinal epithelium. Annu Rev Physiol. 2009; 71:241-60.

[51] Gorbunov NV, Garrison BR, Zhai M, McDaniel DP, Ledney GD, Elliott TB, Kiang JG. Autophagy-mediated defense response of mouse mesenchymal stromal cells (MSCs) to challenge with Escherichia coli. In: Protein Interaction / Book 1; ISBN 979-953-307-577-7. Eds.: Cai J. InTech Open Access Publisher; 2011; www.intechweb.org. pp. 23-44.

[52] Haegebarth A, Perekatt AO, Bie W, Gierut JJ, Tyner AL. Induction of protein tyrosine kinase 6 in mouse intestinal crypt epithelial cells promotes DNA damage-induced apoptosis. Gastroenterology. 2009; 137:945-54.

[53] Wilkins HM, Marquardt K, Lash LH, Linseman DA. Bcl-2 is a novel interacting partner for the 2-oxoglutarate carrier and a key regulator of mitochondrial glutathione. Free Radical Biol \& Med. 2012; 52:410-19. 